\title{
Bilateral spontaneous non-traumatic rupture of the Achilles tendon: a case report
}

\author{
Zubair Khanzada ${ }^{*}$, Ulfin Rethnam¹, David Widdowson² and Ahmed Mirza ${ }^{1}$
}

\begin{abstract}
Introduction: We present an interesting case of spontaneous non-traumatic bilateral rupture of the Achilles tendons, which is a rare condition. Delayed or missed diagnosis of Achilles tendon ruptures by primary treating physicians is relatively common.

Case report: A 78-year-old Caucasian woman presented with spontaneous non-traumatic bilateral rupture of the Achilles tendons. Her symptoms started two days after she took ciprofloxacin $500 \mathrm{mg}$ twice daily for a urinary tract infection and prednisolone $30 \mathrm{mg}$ once daily for chronic obstructive airway disease.

Conclusion: This case report aims to increase the awareness of this rare condition, which should be borne in mind with regard to patients who are on steroid therapy and are concurrently started on fluoroquinolones.
\end{abstract}

\section{Introduction}

Spontaneous non-traumatic rupture is rare and is commonly associated with long-term use of corticosteroids [1] or fluoroquinolones [2]. When prescribed together, steroids and fluoroquinolones can have a potentiating effect, causing an increase in the risk of Achilles tendon rupture [3]. Bilateral spontaneous Achilles tendon rupture is extremely rare, with fewer than 20 cases reported in the literature [4]. We present an interesting case of spontaneous bilateral Achilles tendon rupture.

\section{Case report}

A 78-year-old Caucasian woman presented to the Accident and Emergency Department with spontaneous onset of severe pain in both ankles. There was no history of trauma. The patient was given oral ciprofloxacin hydrochloride $500 \mathrm{mg}$ twice daily for urinary tract infection. She was also given oral prednisolone $30 \mathrm{mg}$ once daily for chronic obstructive airway disease. Two days after starting the medications the patient developed intense bilateral ankle pain. She was unable to walk. The symptoms started on the left side first, followed by the right side a few hours later. There was nothing in the patient's history to suggest chronic Achilles tendinopathy.

\footnotetext{
* Correspondence: zubairshabbir@hotmail.com

'Department of Orthopaedics, Glan Clwyd Hospital, Bodelwyddan, Rhyl, UK
} Full list of author information is available at the end of the article
At the initial assessment, the patient was unable to bear weight because of pain. Both ankles appeared to be swollen with bruising over the Achilles tendon region. There was tenderness over both Achilles tendons near their insertions into the calcaneus with palpable gaps in the substance of the tendons. She had a positive Thompson's test and was unable to perform active plantar flexion with either ankle joint. There was no neurological deficit distally.

A clinical diagnosis of bilateral spontaneous rupture of Achilles tendon was suspected. Because of the rarity of the suspected diagnosis, a differential diagnosis of deep vein thrombosis (DVT) was also taken into consideration. A Doppler imaging study was obtained to rule out DVT, which proved to be negative. Magnetic resonance imaging (MRI) scans were obtained for both ankles, which confirmed bilateral Achilles tendon rupture $5 \mathrm{~cm}$ proximal to insertion into the calcaneus (Figures 1 and 2). There were no features suggestive of pre-existing tendinopathy on the MRI scans.

A decision to apply conservative management was made in consideration of the patient's age, co-morbidities and activity level, as well as the patient's wishes. Steroids and fluoroquinolones were stopped as they were believed to be the causative factor and can interfere with the tendonhealing process.

The patient was placed in bilateral below-knee plasters in gravity equinus for four weeks, in mid-equinus for 


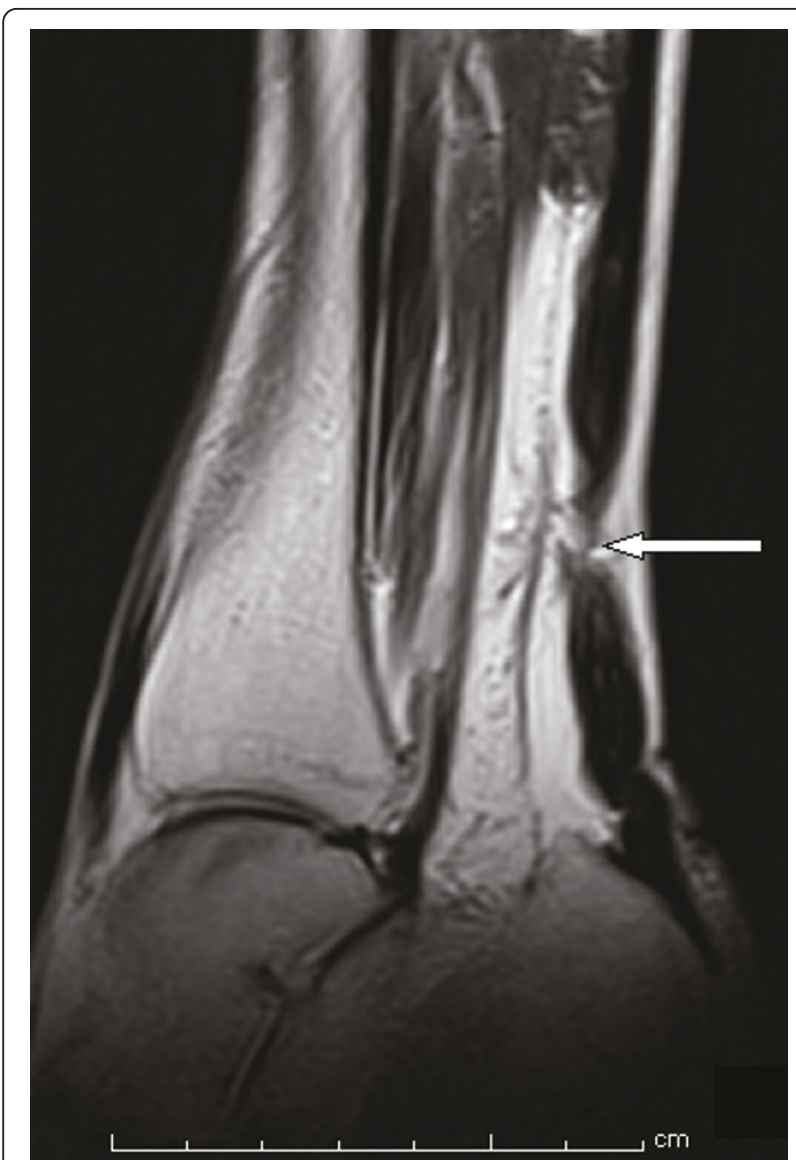

Figure 1 Sagittal view magnetic resonance imaging (MRI) scans of the patient's right ankle showing rupture of the Achilles tendon

two weeks and in a neutral position for two weeks. The patient was followed up at four, eight and 12 weeks. At 12 weeks, both the Achilles tendons had healed. On palpation, the tendons were in continuity, with no gap at the area of the rupture. An assessment of ankle range of movement revealed dorsiflexion of $40^{\circ}$ and plantarflexion $30^{\circ}$ bilaterally. The patient's American Orthopaedic Foot and Ankle Score (AOFAS) for foot and ankle disorders for her hind foot had improved from 18 on presentation to 61 at the final follow-up examination. The patient was able to bear weight and mobilize with a stick. Some stiffness in both ankle joints continued as residual symptoms, for which physiotherapy was continued.

\section{Discussion}

The Achilles tendon is the tendinous extension of three muscles in the lower leg: the gastrocnemius, the soleus and the plantaris. It is the thickest and strongest tendon in the body. It is inserted into the middle part of the posterior surface of the calcaneum. The primary

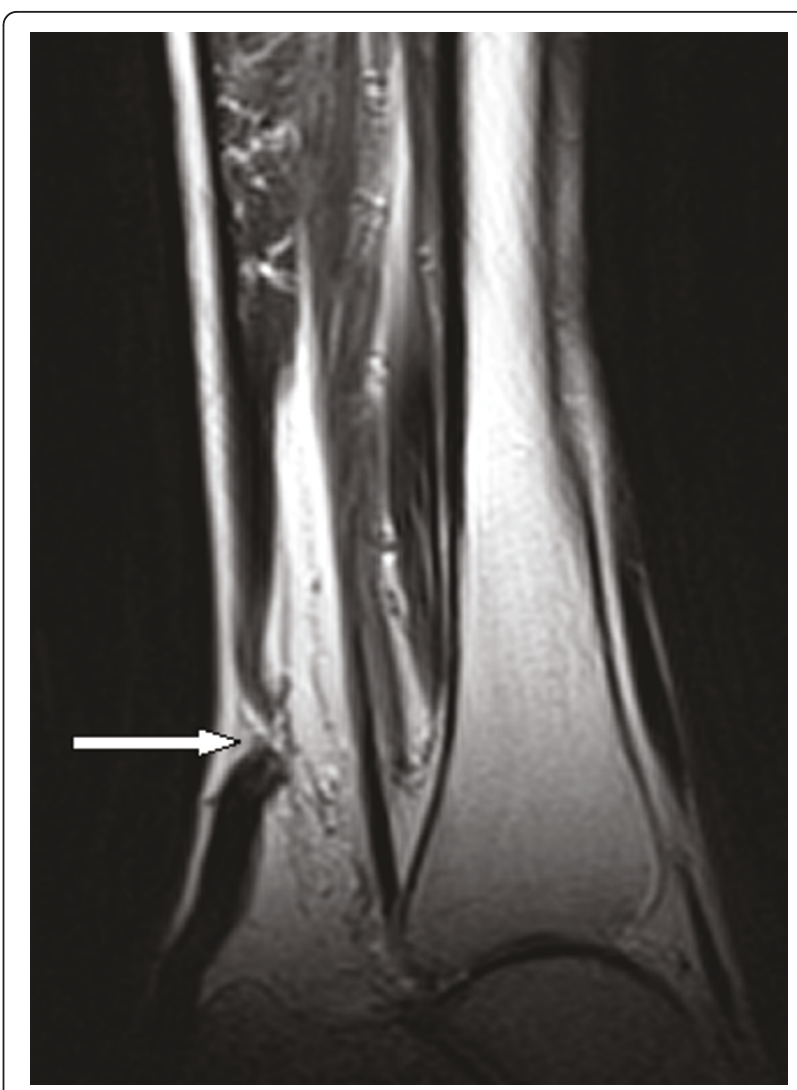

Figure 2 Sagittal view MRI scans of the patient's left ankle showing rupture of the Achilles tendon.

function of the Achilles tendon is to transmit the power of the calf to the foot, enabling walking and running. Achilles tendon ruptures account for $20 \%$ of all large tendon ruptures [4].

Achilles tendon tears are usually traumatic, resulting from a large force on a normal tendon or a physiological force on a weak tendon. The mechanism usually involves eccentric loading on a dorsiflexed ankle with the knee extended (soleus and gastrocnemius on maximal stretch). The majority of tears occur in the watershed area, an area of structural weakness located approximately $6 \mathrm{~cm}$ proximal to the tendon insertion on the calcaneus [5].

In most cases reported in the literature, bilateral spontaneous rupture of the Achilles tendon has been associated with corticosteroid use. The exact mechanism by which corticosteroids cause tendon damage is not clear. It is said that steroids have the ability to alter the collagen structure of tendons by contributing to dysplasia of collagen fibrils, thus reducing the tensile strength of the tendon [6]. Corticosteroids can also interfere with collagen fiber cross-linking, which can lead to disruption in the normal healing process of the tendon $[1,6,7]$.

The other association of spontaneous rupture of the Achilles tendon is with the use of fluoroquinolones 
[8,9]. Van der Linden et al. [10] described bilateral Achilles tendon ruptures two, three and six days after initial treatment with fluoroquinolones and bilateral Achilles tendinitis one, two, and three days after initial treatment with fluoroquinolones. Animal studies have suggested that chelation of magnesium and free radical formation result in oxidative stress, leading to a direct toxic effect on collagen [11-14].

The reported incidence of spontaneous Achilles tendon rupture is $0.02 \%$ in the Western population. Less than $1 \%$ of patients have simultaneous bilateral rupture [4].

Our case report is of interest because the patient had only a short course (two days) of fluoroquinolones and oral steroids. Her initial presentation did take us by surprise. With conservative treatment, the final outcome was good. This rare condition can be easily missed if one is not aware of the possibility of spontaneous rupture of the Achilles tendon with the concurrent use of steroids and fluoroquinolones.

\section{Conclusion}

This case report aims to increase the awareness of the risk of this rare condition in patients who are started on steroids and fluoroquinolones concurrently even for a short period.

\section{Consent}

Written informed consent was obtained from the patient for publication of this case report and any accompanying images. A copy of the written consent is available for review by the editor-in-chief of this journal.

\footnotetext{
Author details

${ }^{1}$ Department of Orthopaedics, Glan Clwyd Hospital, Bodelwyddan, Rhyl, UK. 2Department of Radiology, Glan Clwyd Hospital, Bodelwyddan, Rhyl, UK.
}

\section{Authors' contributions}

ZK made substantial contributions by identifying, writing and carrying out the literature search. UR was involved in critically revising the case report. DW helped in performing the imaging and made the imaging studies. AM gave final approval of the manuscript version to be published.

All authors have read and approved the final manuscript.

\section{Competing interests}

The authors declare that they have no competing interests.

Received: 26 January 2010 Accepted: 30 June 2011

Published: 30 June 2011

\section{References}

1. Orava S, Hurme M, Leppilahti J: Bilateral Achilles tendon rupture: a report on two cases. Scand J Med Sci Sports 1996, 6:309-312.

2. Lee WT, Collins JF: Ciprofloxacin associated bilateral Achilles tendon rupture. Aust N Z J Med 1992, 22:500.

3. Van der Linden PD, Sturkenboom MC, Herings RM, Leufkens HM, Rowlands S, Stricker BH: Increased risk of Achilles tendon rupture with quinolone antibacterial use, especially in elderly patients taking oral corticosteroids. Arch Intern Med 2003, 163:1801-1807.

4. Habusta SF: Bilateral simultaneous rupture of the Achilles tendon: a rare traumatic injury. Clin Orthop Relat Res 1995, 320:231-234.
5. Inglis AE, Sculco TP: Surgical repair of rupture of the tendo Achillis. Clin Orthop Relat Res 1981, 156:160-169.

6. Kelly M, Dodds M, Huntley JS, Robinson CM: Bilateral concurrent rupture of the Achilles tendon in the absence of risk factors. Hosp Med 2004, 65:310-311.

7. Kotnis RA, Halstead JC, Hormbrey PJ: Atraumatic bilateral Achilles tendon rupture: an association of systemic steroid treatment. J Accid Emerg Med 1999, 16:378-379.

8. Kowatari K, Nakashima K, Ono A, Yoshihara M, Amano M, Toh S: Levofloxacin-induced bilateral Achilles tendon rupture: a case report and review of the literature. J Orthop Sci 2004, 9:186-190.

9. Poon CC, Sundaram NA: Spontaneous bilateral Achilles tendon rupture associated with ciprofloxacin. Med J Aust 1997, 166:665.

10. Van der Linden PD, van Puijenbroek EP, Feenstra J, Veld BA, Sturkenboom MC, Herings RM, Leufkens HG, Stricker BH: Tendon disorders attributed to fluoroquinolones: a study on 42 spontaneous reports in the period 1988 to 1998. Arthritis Rheum 2001, 45:235-239.

11. Simonin MA, Gegout-Pottie P, Minn A, Gillet P, Netter P, Terlain B: Pefloxacin-induced Achilles tendon toxicity in rodents: biochemical changes in proteoglycan synthesis and oxidative damage to collagen. Antimicrob Agents Chemother 44:867-872.

12. Ribard P, Audisio F, Kahn MF, De Bandt M, Jorgensen C, Hayem G, Meyer O, Palazzo E: Seven Achilles tendinitis including 3 complicated by rupture during fluoroquinolone therapy. J Rheumatol 19:1479-1481.

13. Kashida Y, Kato M: Characterization of fluoroquinolone-induced Achilles tendon toxicity in rats: comparison of toxicities of 10 fluoroquinolones and effects of anti-inflammatory compounds. Antimicrob Agents Chemother 41:2389-2393.

14. Casparian JM, Luchi M, Moffat RE, Hinthorn D: Quinolones and tendon ruptures. South Med J 93:488-491.

doi:10.1186/1752-1947-5-263

Cite this article as: Khanzada et al: Bilateral spontaneous non-traumatic rupture of the Achilles tendon: a case report. Journal of Medical Case Reports 2011 5:263.

\section{Submit your next manuscript to BioMed Central and take full advantage of:}

- Convenient online submission

- Thorough peer review

- No space constraints or color figure charges

- Immediate publication on acceptance

- Inclusion in PubMed, CAS, Scopus and Google Scholar

- Research which is freely available for redistribution 